$$
\begin{aligned}
& \text { SAND- }-98-8540 C
\end{aligned}
$$

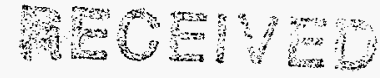

$$
\begin{aligned}
& \text { MAY I I } \\
& 0 \text { STI } \\
& \text { CONF-980202- }
\end{aligned}
$$

Please include the following Notice as part of the Acknowledgment section:

The rabmitted masecoript bes beed authosed by a oontreotor of the Unilted States Corersiment under oontroot. Acoordingly the United States Govexpment zetaine a non-exclunive, soyalty-tree llowee to publleh or reproduon the problinbed form of this costribution, or allow others to do 10 , to United States Gorernment pars. poren

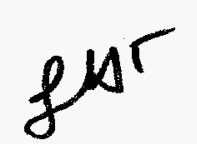




\section{DISCLAIMER}

This report was prepared as an account of work sponsored by an agency of the United States Government. Neither the United States Government nor any agency thereof, nor any of their employees, makes any warranty, express or implied, or assumes any legal liability or responsibility for the accuracy, completeness, or usefulness of any information, apparatus, product, or process disclosed. or represents that its use would not infringe privately owned rights. Reference herein to any specific commercial product, process, or service by trade name, trademark, manufac. turer, or otherwise does not necessarily constitute or imply its endorsement, recom. mendation, or favoring by the United States Government or any agency thereof. The views and opinions of authors expressed herein do not necessarily state or reflect those of the United States Government or any agency thereof. 


\section{DISCLAIMER}

Portions of this document may be illegible in electronic image products. Images are produced from the best available original document. 


\title{
IMPURITY EFFECTS ON THE ADHESION OF ALUMINUM FILMS ON \\ SAPPHIRE SUBSTRATES
}

\author{
J.A. SCHNEIDER ${ }^{1}$, S.E. GUTHRIE ${ }^{1}$, M.D. KRIESE ${ }^{2}$, W.M. CLIFT ${ }^{1}$, N.R. MOODY ${ }^{1}$ \\ 1 Sandia National Laboratories, Livermore, CA 94551 \\ 2 Dept. of Chemical Engineering and Materials Science, \\ University of Minnesota, Minneapolis, MN 55455
}

\section{ABSTRACT}

The adhesion of aluminum (Al) films onto sapphire substrates in the presence of controlled contaminants is being investigated. In this study, adhesion strength is evaluated by continuous scratch and nanoindentation tests to induce delamination of the $\mathrm{Al}$ film from the sapphire substrate. If delamination blisters or spallations can be induced, then fracture mechanics based models can be used to calculate the fracture energy or work of adhesion based on the radius of the blister. Initial specimens of $178 \mathrm{~nm}$ thick Al films were vapor deposited onto (0001) oriented sapphire substrates with a 5-10 nm layer of carbon sputter deposited onto the sapphire surface of selected samples. Continuous scratch tests promoted blistering of the film in specimens with carbon on the sapphire surface. Delamination blisters could not be induced by continuous indentation testing in samples with or without carbon at the interface. An overlayer of sputtered tantalum (Ta) was then used on a second set of $500 \mathrm{~nm}$ thick $\mathrm{Al}$ films with and without $10-20 \mathrm{~nm}$ of sputtered carbon on the sapphire surface to promote delaminations. With Ta overlayers, continuous nanoindentation techniques induced larger diameter delamination blisters in the specimens with carbon, than in the specimens without carbon. Resistance to blistering, or smaller induced blisters, indicates a higher interfacial strength. 


\section{INTRODUCTION}

A common concern to those working with thin films or coatings is adhesion to the substrate or material of interest. In the electronics area these are commonly thin ductile metal films on insulating ceramic substrates. The adherence of these films depends on both the presence of contaminants which can weaken the adhesive strength, and the presence of residual stresses which can overcome the interfacial strength. Of interest is how to measure and interpret the effect of contaminants on this adhesion or interfacial strength.

Methods for evaluating the adhesion of thin films to substrates generally fall into 2 categories. Semi-quantitative tests, such as peel or bend tests, while providing a comparative basis for the adhesion, cannot be directly related to material mechanisms of adhesion $[1,2]$. More quantitative methods utilize linear elastic fracture mechanics to allow direct assessment of the critical energies of interfacial adhesion [3-7]. These methods use various techniques to initiate and propagate a delamination between the film and the substrate such as the blister technique $[8,9]$, or nanoindentation techniques. Nanoindentation typically uses a device which measures the continuous load and displacement of a diamond indenter tip which is either pushed into the film past the substrate in a standard continuous indentation test, or pushed into and across the film in a standard microscratch test. Formulas used in this study to relate the energy release rate of the interface crack to the film buckling parameters were those derived by Venkataraman, et. al. [10-12] for continuous microscatch testing, and those derived by Marshall, Evans, and Hutchinson [13, 14] and Hutchinson and Suo [6] for continuous indentation testing. However, application of these techniques to ductile or strongly adhering films has been limited due to the difficulty in developing sufficient elastic strain energy for delamination [15]. Use of highly stressed overlayers deposited over the film of interest have been reported to reduce this limitation $[2,16,17,30]$. In this study, nanoindentation techniques applicable to asdeposited films are evaluated. 


\section{MATERIALS AND PROCEDURE}

The effect of contaminants on adhesion was investigated by sputtering 5 to $20 \mathrm{~nm}$ of carbon on (0001) sapphire substrates prior to deposition of $\mathrm{Al}$ films. A graphite target was used as the carbon source. Prior to deposition, the sapphire substrate surface was subjected to an $\mathrm{HCl}$ etch, de-ionized water rinse, $\mathrm{N}_{2}$ drying and mounted in an analysis chamber with a base pressure of $2 \times 10^{-11}$ torr. The substrate was heated to $250^{\circ} \mathrm{C}$ and held for $1 \mathrm{hr}$ to drive off moisture. Evolving species were verified as water vapor by an in-situ quadrapole mass spectrometer. Surface cleanliness was verified by Auger analysis before and after all processes. After characterization, the sample was moved under vacuum directly into an ancillary chamber for film deposition. Film thickness was determined in-situ by a quartz crystal deposition monitor and subsequently verified using independent stylus measurements.

Aluminum thin films of 178 and $500 \mathrm{~nm}$ were deposited by physical vapor deposition (PVD) onto the smooth single crystal sapphire substrates at a background pressure of $5 \times 10^{-9}$ torr. The substrates were not actively heated, but the temperature rose during deposition from an ambient $24^{\circ} \mathrm{C}$ to $34^{\circ} \mathrm{C}$ due to radiant heating from the source. Tantalum overlayers, $1000 \mathrm{~nm}$ thick, were deposited by DC magnetron sputtering onto the surface of the $500 \mathrm{~nm}$ thick aluminum films using low pressure (5 mTorr) argon gas.

A Rigaku X-ray diffraction (XRD) system with a thin film detection system and $\mathrm{Cu}-\mathrm{k} \alpha$ radiation was used to characterize the films. Out-of-plane strain, indicated by shifts in the $2 \theta$ peak position, was used to calculate the in-plane stress, assuming isotropic elasticity [18].

Hardness and elastic moduli of the $\mathrm{Al}$ and Ta films on sapphire were calculated for each indent from continuous indentation loads and displacement data recorded with a Nanoindenter $I^{\circledR}$ 
system. A triangular (Berkovich) pyramid-shape diamond indenter tip, with approximately $320 \mathrm{~nm}$ root radius, was driven to a maximum depth of $500 \mathrm{~nm}$ at a constant loading rate of 30 $\mu \mathrm{N} / \mathrm{s}$. The Berkovich indenter tip was previously calibrated by indentations into a material of known modulus to correlate the contact area as a function of indenter depth. Use of this area function and the recorded depth of the indenter allowed calculation of the elastic moduli and hardness properties using the method of Oliver and Pharr [19].

For continuous scratch or indentation testing to induce delamination of the film from the substrate, the Nanoindenter was configured with a conical diamond indenter with a nominal $1 \mu \mathrm{m}$ tip radius and a $90^{\circ}$ included angle. In continuous scratch tests, the tip is simultaneously driven into the films at a rate of $15 \mathrm{~nm} / \mathrm{s}$ and across the films at $0.5 \mu \mathrm{m} / \mathrm{s}$, and in continuous indentation tests, the tip was driven into the film at a constant loading rate of $300 \mu \mathrm{N} / \mathrm{s}$. In addition to the continuous recording of the normal load and indenter depth during each test, the tangential and lateral loads were also monitored during a scratch test. From blistering events, the fracture energy or work of adhesion of the film to the substrate can be calculated using the elastic approach of Venkataraman, et. al. [10-12] for scratch induced delamination and the elastic approach of Marshall, Evans, and Hutchinson [13, 14] for indentation induced delamination.

The work of adhesion $\left(\mathrm{W}_{\mathrm{a}}\right)$ is calculated from the strain energy release rate $(\mathrm{G})$ for fracture of thin films. A crack induced at the interface between the film and substrate advances when the strain energy release rate is equal to the interfacial energy $\left(\Gamma_{1}\right)$ as summarized in Eqn. 1 [6].

$$
\mathrm{W}_{\mathrm{a}}=\mathrm{G}=\Gamma_{\mathrm{I}}
$$

The analyses of the nanoindentation analyses utilize the thin film elastic modulus, E, shear modulus, $\mu$,and Poisson's ratio, $v$, along with the thin film thickness, $t$, and delamination 
radius, a, to determine strain energy release rates. For scratch induced delamination, total strain energy $\left(\mathrm{G}_{0}\right)$ available is a combination of the shear stresses $(\tau)$ and normal stresses $(\sigma)$, accounted for as summarized in Eqn. 2 [6, 10-14]:

$$
G_{o}=\left(1-v^{2}\right) \Sigma\left(\frac{\tau^{2}}{2 \mu}+\frac{\sigma^{2}}{2 E}\right) \mathrm{t}
$$

Of the total stored strain energy $\left(\mathrm{G}_{0}\right)$ in the film, only a portion $(\mathrm{G})$ is released when the crack advances at the interface as summarized in Eqn. 3 [6].

$$
G=\frac{G_{o}}{(1+0.9021(1-v))}\left[\left(1-\frac{\sigma_{B}}{\sigma}\right)^{2}\right]
$$

The critical buckling stress $\left(\sigma_{\mathrm{B}}\right)$ is the critical buckling stress for a clamped circular plate is given by Eqn. 4 [6].

$$
\sigma_{B}=\frac{k}{12}\left(\frac{E}{1-v^{2}}\right)\left(\frac{t}{a}\right)^{2}
$$

where $\mathrm{k}$ is equal to 42.7 for a plate pinned at the center during buckling under indentation loading ( $\mathrm{k}=14.7$ for an unconstrained plate). For indentation induced delamination, the strain energy $\left(G_{0}\right)$ stored in the film due to residual stress in the film remains described by Eqn. 2 with $\tau=0$ and $\sigma=\sigma_{R}$ For indendation of a single thin film, the portion released ( $G$ ) is given by Eqn. $5[6,13,14]$. 


$$
\mathrm{G}=\frac{\mathrm{G}_{\mathrm{o}}}{1+0.9021(1-\mathrm{v})}\left[\left\{1-\left(\frac{\sigma_{\mathrm{B}}}{\sigma_{\mathrm{R}}}\right)^{2}\right\}+\left\{\left(\frac{\sigma_{\mathrm{I}}}{\sigma_{\mathrm{R}}}\right)^{2}\right\}\left\{\frac{1+\mathrm{v}}{2+1.8042(1-v)}+\frac{2 \sigma_{\mathrm{B}}}{\sigma_{\mathrm{I}}}-1\right\}\right]
$$

where $\sigma_{\mathrm{I}}$ is the indentation stress determined from volume-conserving accommodation of the indentation volume $V_{I}$, and is given by Eqn. 6 [14]:

$$
\sigma_{\mathrm{I}}=\varepsilon_{\mathrm{I}} \frac{\mathrm{E}}{(1-v)}=\frac{\mathrm{V}_{\mathrm{I}} \mathrm{E}}{2 \pi \mathrm{h}^{2}(1-\mathrm{v})}
$$

Kriese, et. al. have used the model of Marshall and Evans [14] as a basis for determination of the strain energy release rate occurring with indentation of a multilayer thin film system $[17,20]$.

\section{RESULTS AND DISCUSSION}

Texturing observed in the XRD analysis of the Ta films deposited directly on sapphire (Figure 1a) and over the Al films (Figure 1b) are similar. A strong (002) orientation of the $\beta$-Ta phase is indicative of a compressively stressed Ta film [21,22]. Spontaneous blisters observed in the Ta films soon after deposition were used to calculate an upper bound for the residual stress in the film. Applying Eqn. 4 for the critical buckling stress of a clamped plate [6] to the observed $40 \mu \mathrm{m}$ nominal diameter blisters, a residual stress level of $1.8 \mathrm{GPa}$ in the film is required to drive the delamination induced buckling. Since this is an elastic solution, any plastic deformation would relieve some level of residual stress. A lower bound of typical residual stress levels in sputtered Ta films is provided in the review by Thornton and Hoffman [23] in which use of low argon (5 mTorr) sputtered gas pressures resulted in a compressive residual stress level of $0.4 \mathrm{GPa}$ in $200 \mathrm{~nm}$ thick Ta films. Using the $2 \theta$ peak position shift of 
the Ta film on sapphire, a biaxial, in-plane residual compressive stress of 0.8 to $1.0 \mathrm{GPa}$ was calculated for the films in this study.

Al films on sapphire display a (111) texture as shown in both the XRD analysis with the Ta overlayer in Figure 1a, and without the Ta layer in Figure 1c. The $2 \theta$ peak position shift of the $\mathrm{Al}$ film on sapphire was used to calculate a biaxial, in-plane tensile stress in the range of 0.01 to $0.05 \mathrm{GPa}$. Stress levels in the $\mathrm{Al}$ films are significantly less that those in the Ta films.

Elastic modulus and hardness calculated for the $\mathrm{Al}$ and $\mathrm{Ta}$ films, respectively, are shown as a function of indentation depth, in Figures 4 and 5. Indentations were made to a maximum depth of $500 \mathrm{~nm}$, although only the indentation information from the top $10 \%$ of the film was used to avoid the influence of the substrate in determining the film properties. Indentations in the $\beta-T a$ film on sapphire indicate a hardness of $16.6 \pm 1.8 \mathrm{GPa}$ and an elastic modulus of $266.7 \pm 23.4$ $\mathrm{GPa}$. This is in close agreement with the published hardness of $16-18 \mathrm{GPa}$ for (002) oriented $\beta$-Ta films [22]. Textured (111) Al films on sapphire indicate a hardness of $0.7 \pm 0.2 \mathrm{GPa}$ and an elastic modulus of $61.3 \pm 9.0 \mathrm{GPa}$. The hardness of the $\mathrm{Al}$ film is slightly higher than that of bulk (111) single crystal $\mathrm{Al}$, which is not uncommon in thin film layers [24]. Influence of the sapphire substrate is observed in the elastic modulus measurements as they increase with indentation depth for both the $\mathrm{Al}$ and $\mathrm{Ta}$ films.

Continuous microscratch testing resulted in blistering of the film with carbon at the interface as shown in Figure 4a. Loads of $2.5 \mathrm{mN}$ initiate the blisters at indenter penetrations of $800 \mathrm{~nm}$ into the material. In films without carbon, or with a "clean" surface at the film interface (Figure 4b), no evidence of blistering was observed. In repeat testing after 6 months, the blistering could not be reproduced by additional microscratch testing in the sample with carbon at the interface. This indicates a higher degree of residual stresses present in the film immediately after deposition which contributes to the indentation induced delamination. As the stresses 
relax in the film with time, the amount of available elastic strain energy for delamination also decreases. Although no comparative value can be obtained for $\mathrm{Al}$ films on clean substrates in this study, the initial blistering event did provide data for calculation of a fracture energy or elastic strain energy release rate of $0.02 \mathrm{~J} / \mathrm{m}^{2}$ using the approach of Venkataraman, et. al. [10-12]. This data indicates a weak bonding similar to results in earlier microscratch testing of $90 \mathrm{~nm}$ thick Al films on sapphire with a contamination oxide layer at the interface, in which an elastic strain energy release rate of $0.01 \mathrm{~J} / \mathrm{m}^{2}$ was calculated [25].

Continuous indentation tests with a conical indenter in the $\mathrm{Al}$ films on sapphire were unsuccessful in driving delamination blistering in the $\mathrm{Al}$ films; thus, other techniques were evaluated to increase the available elastic strain energy in the $\mathrm{Al}$ film. Highly stressed overlayers of $\mathrm{Ta}$ were deposited over the $\mathrm{Al}$ films and the continuous indentation tests were repeated. Delamination blisters induced from these tests are shown in Figure 5a for the sample with carbon at the $\mathrm{Al} /$ sapphire interface, and in Figure $5 \mathrm{~b}$ for the clean interface sample. A load of $250 \mu \mathrm{N}$ was required to induce blistering in the sample with the clean interface and was applied to both samples.

Modified calculations, based on the methods of Marshall, Evans, and Hutchinson [13, 14], which take into account the bi-layer film properties $[17,20]$ and were applied to the indentation driven delamination blisters. The calculated fracture energies to drive the larger diameter delamination blisters in the films with $10-20 \mathrm{~nm}$ of carbon at the interface were in the range of 0.8 to $1.3 \mathrm{~J} / \mathrm{m}^{2}$. Although these values are slightly higher than the typical van der Waals forces of 0.05 to $0.7 \mathrm{~J} / \mathrm{m}^{2}$ [26-29], the low fracture energy does indicate a weak type of bond. A higher fracture energy of 5.1-6.1 J// $\mathrm{m}^{2}$ was calculated for the smaller diameter delamination blisters observed in the films with the clean interface indicating a stronger bond, possibly on the order of chemical bonding. Similar results have been published for $500 \mathrm{~nm}$ thick $\mathrm{Ta}_{2} \mathrm{~N}$ overlayers on $178 \mathrm{~nm}$ thick Al films in which a fracture energy of $7 \mathrm{~J} / \mathrm{m}^{2}$ was calculated [30]. 
The sample with carbon at the sapphire interface (Figure 5a) delaminated at all indenter loads up to $250 \mu \mathrm{m}$. This delamination continued over time and after 1 month the sample displayed classical "telephone cording", shown in Figure 6, which is characteristically exhibited in highly stressed films. Complete delamination of the film provided the opportunity to inspect the interface surfaces of both the sapphire substrate and the Al film. Sputtering Auger analysis of the sapphire substrate, shown in Figure 7a, indicates a residual carbon thickness of $10 \mathrm{~nm}$ before the $\mathrm{Al}$ spectra from the sapphire substrate is observed. Figure $7 \mathrm{~b}$ shows the results of the sputtering Auger analysis of the interface side of the Al film. An initial layer of $5 \mathrm{~nm}$ of carbon is present which transitions to a carbide, possibly AlC, before exposing the underlying $\mathrm{Al}$.

Evidence of fracture within the carbon layer at the interface supports similar trends reported in whisker pull out tests in which carbon layer formation has been reported to decrease fracture resistance [31]. Weak bonding has been reported for a range of interfacial carbon layer thickness. Brennon $[32,33]$ cited extensive fiber pull out occurring in composites with a 10-40 $\mathrm{nm}$ layer of carbon present attributed to debonding within the carbon layer. The effect on shear strength was recently reported by Dehn, et. al [34] in which a decrease in adhesion of copper to sapphire was observed by incorporating up to $110 \mathrm{~nm}$ thick carbon layers. This study suggests the debonding in the carbon occurs in thinner layers than previously reported. Presence of a carbide suggests that a reaction may be occurring between the $\mathrm{Al}$ and the carbon, indicating a critical carbon thickness for transition from a weakly bonded to a strongly bonded Al films on sapphire substrates. 


\section{SUMMARY}

To obtain a value for adhesion of Al films on "clean" sapphire substrates, highly stressed overlayers of $\mathrm{Ta}$ were required to promote delamination blistering. The higher adhesion strength for these films indicates the formation of a stronger, possibly chemical type of bond. The use of highly stressed overlayers appears to increase the driving force for indentation induced delamination of highly ductile films which otherwise are unable to support sufficient elastic strain energy to promote interfacial delamination.

Both microscratch and indentation tests indicate a weak bond between the $\mathrm{Al}$ and sapphire substrates when a 5-20 nm layer of carbon is present. Sputtering Auger analysis indicates the fracture occurred in a thinner carbon layer than previously reported. The presence of a carbide adjacent to the $\mathrm{Al}$ film interface suggests a possible transition from a weakly bonded to a strongly bonded $\mathrm{Al}$ films on sapphire substrates.

\section{ACKNOWLEDGMENTS}

This work was supported by the U.S. Department of Energy under Contract \#DE-AC04-

94AL85000. The authors also wish to thank D. Boehme at Sandia Labs for assistance with the XRD analysis and A. Strojny at Univ. of Minnesota for helpful discussions.

\section{REFERENCES}

1. M. Ohring, The Materials Science of Thin Films, (Academic Press, Inc., New York, 1992).

2. A. Bagchi, A.G. Evans, Thin Solid Films, 286, 203 (1996)

3. Z. Suo, J.W. Hutchinson, Int. J. of Fracture, 43, 1 (1990). 
4. J.R. Rice, J. Appl. Mech., 55, 98 (1988).

5. A.G. Evans, M Ruhle, B.J. Dalgleish, P.G. Charalambides, Mater. Sci. Engr., A126, 53 (1990).

6. J.W. Hutchinson Z. Suo, Adv. in Applied Mechanics, (Academic Press, Inc., New York, 1992).

7. A.G. Evans, M.D. Drory, M.S. Hu, J. Mater. Res., 3, 1043 (1988).

8. H. Chai, Int. J. Fracture, 46, 237 (1990).

9. H. M. Jensen, Engr. J. Fract. Mech., 40, 475 (1991).

10. S.K. Venkataraman, D.L. Kohlstedt, W.W. Gerberich, J. Mater. Res., 7, $1126(1992)$.

11. S.K. Venkataraman, D.L. Kohlstedt, W.W. Gerberich, Thin Solid Filkms, 223, 269 (1993).

12. N.R. Moody, R.Q. Hwang, S. Venkataraman, J.E. Angelo, D.P. Norwood, W.W. Gerberich, Acta mater., 46 [2] 585 (1998).

13. A.G. Evans, J.W. Hutchinson, Int. J. Solids Structures, 20 [5] 455 (1984).

14. D.B. Marshall, A.G. Evans, J. Appl. Phys., 56 [10] 2632 (1984).

15. M.R. Turner, A.G. Evans, Acta Mater, 44, 863 (1996).

16. A. Bagchi, G.E. Lucas, Z. Suo, A.G. Evans, J. Mater. Res., 9, 1734 (1994).

17. M.D. Kriese, N.R. Moody, W.W. Gerberich, MRS Symp. Proc., 473, 39, ed. J.J. Clement, R.R. Keller, K.S. Krisch, J.E. Sanchez Jr., and Z. Suo (1997).

18. D.B. Cullity, Elements of X-Ray Diffraction, (Addison-Wesley, Reading, Massachusetts, 1967).

19. W.C. Oliver, G.M. Pharr, J. Mat. Res., 7, 1564 (1992).

20. M.D. Kriese, N.R. Moody, W.W. Gerberich, to be submitted J. Mat. Res. (1998). 
21. M. Oda, A. Ozawa, S. Ohki, H. Yoshihara, Jpn. J. Appl. Phys, 11, 2616 (1990).

22. R. Saha, J.A. Barnard, J. Cry. Growth, 174, 495 (1997).

23. J.A. Thorton, D.W. Hoffman, Thin Solid Films, 171, 5 (1989).

24. M.F. Doerner, D.S. Gardner, W.D. Nix, J. Mater. Res., 1, 845 (1986).

25. N.R. Moody, D. Medlin, S. Guthrie, R.Q. Hwang, K.F. McCarty, MRS Symp Proc., 403, 145 (1996).

26. K.L. Chopra, Thin Film Phenomena, (McGraw-Hill Book Co., New York, 1969).

27. M.T. Laugier, Thin Solid Films, 117, 243 (1984).

28. D.C. Agrawal, R. Raj, Mat. Sci. Engr., A126, 125 (1990).

29. P. Benjamin, C. Weaver, Proc. Roy. Soc. London, A252, 516 (1961).

30. D.F. Bahr, J.W. Hoehn, N.R. Moody, W.W. Gerberich, Acta mater., 45 [12], 5163 (1997).

31. R.J. Kerans, R.S. Hay, N.J. Pagano, Cer. Bull., 68 [2], 429 (1989).

32. J.J. Brennan, Tailoring Multiphase and Composite Ceramics, ed. R.T. Tressler, G.L. Messing, C.G. Pantano, R.E. Newnham, 549 (1986).

33. J.J. Brennan, ONR Tech. Report R87-917546-4 (1987).

34. G. Dehm, R. Raj, M. Ruhle, Mat. Sci. Forum, 207-209, 597 (1996). 
FIGURE CAPTIONS

Figure 1. $\quad \mathrm{XRD}$ analysis of $\mathrm{Al}$ and Ta films deposited on sapphire substrates.

Predominant (002) orientation is observed in $1000 \mathrm{~nm}$ thick sputtered $\beta$-Ta film deposited directly on sapphire substrate (a) and over a $500 \mathrm{~nm}$ thick PVD Al film on sapphire substrate (b). Deposition of the Ta film on the Al film does not change the (111) texture observed in the $500 \mathrm{~nm}$ thick Al films on sapphire without the Ta film overlayer(c).

Figure 2. Nanoindentation techniques were used to calculate the elastic modulus (a) and hardness (b) values for the $500 \mathrm{~nm}$ thick $\mathrm{Al}$ films on sapphire substrates. Reference values for the corresponding bulk material properties are indicated by the horizontal lines.

Figure 3. Nanoindentation techniques were used to calculate the elastic modulus (a) and hardness (b) values for $1000 \mathrm{~nm}$ thick $\beta$-Ta films on sapphire substrates. Reference values for the corresponding bulk material properties are indicated by the horizontal lines

Figure 4. Microscratch tests of the $178 \mathrm{~nm} \mathrm{Al} \mathrm{films} \mathrm{on} \mathrm{sapphire} \mathrm{were} \mathrm{used} \mathrm{to} \mathrm{evaluate} \mathrm{the}$ effects of 5-10 $\mathrm{nm}$ of carbon at the interface. Light micrographs show a blister which formed as a $100 \mu \mathrm{m}$ long scratch was made in the film with a $5-10 \mathrm{~nm}$ layer of carbon at the interface (a) but not in the one with a "clean" sapphire substrate (b).

Figure 5. Nanoindentation tests were used to induced blisters in the samples with $\mathrm{Ta} / \mathrm{Al}$ films on sapphire under a $250 \mathrm{mN}$ load. Larger diameter blisters are observed in the light micrograph images in the sample with $10-20 \mathrm{~nm}$ of carbon at the interface (a) than in the sample with the "clean" interface (b). 
Figure 6. The Ta coated $\mathrm{Al}$ films continued to delamination over time in samples with carbon at the sapphire interface. Classic "telephone cord" blisters, typically observed in highly stressed films, are show in this light micrograph of the film surface.

Figure 7. Separation of the film from the substrate allowed sputtering Auger analysis of the delaminated regions. A $10 \mathrm{~nm}$ residual carbon layer remains on the sapphire substrate interface surface (a). On the $\mathrm{Al}$ film interface surface (b) , a $5 \mathrm{~nm}$ layer of carbon layer remains, indicating the fracture occurred in the carbon layer. Carbide formation is noted between the carbon and $\mathrm{Al}$. 


\section{Intensity}

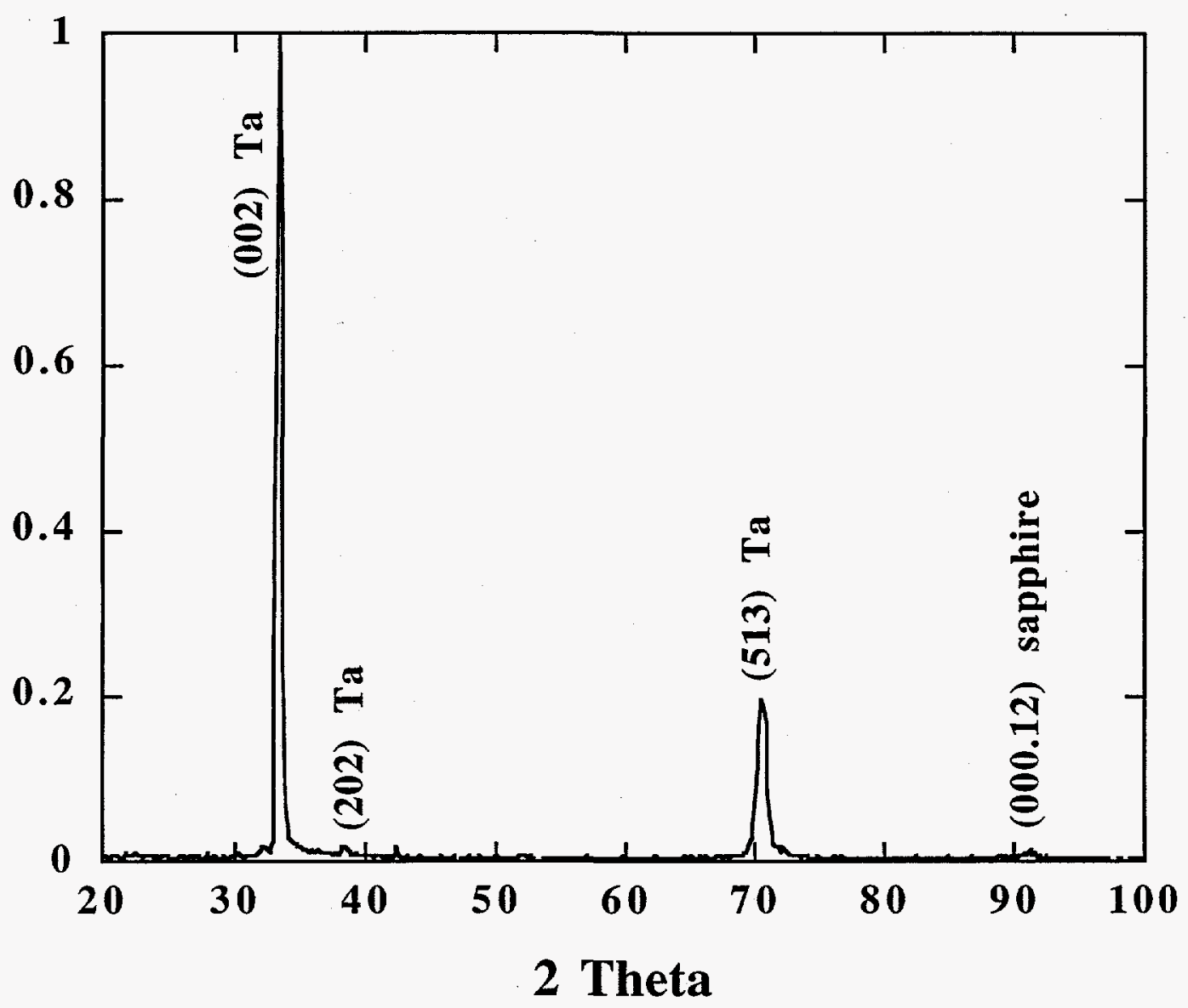

(a)

Figure 1. $\quad \mathrm{XRD}$ analysis of $\mathrm{Al}$ and Ta films deposited on sapphire substrates.

Predominant (002) orientation is observed in $1000 \mathrm{~nm}$ thick sputtered $\beta$-Ta film deposited directly on sapphire substrate (a) and over a $500 \mathrm{~nm}$ thick PVD Al film on sapphire substrate (b). Deposition of the Ta film on the Al film does not change the (111) texture observed in the $500 \mathrm{~nm}$ thick Al films on sapphire without the Ta film overlayer (c). 


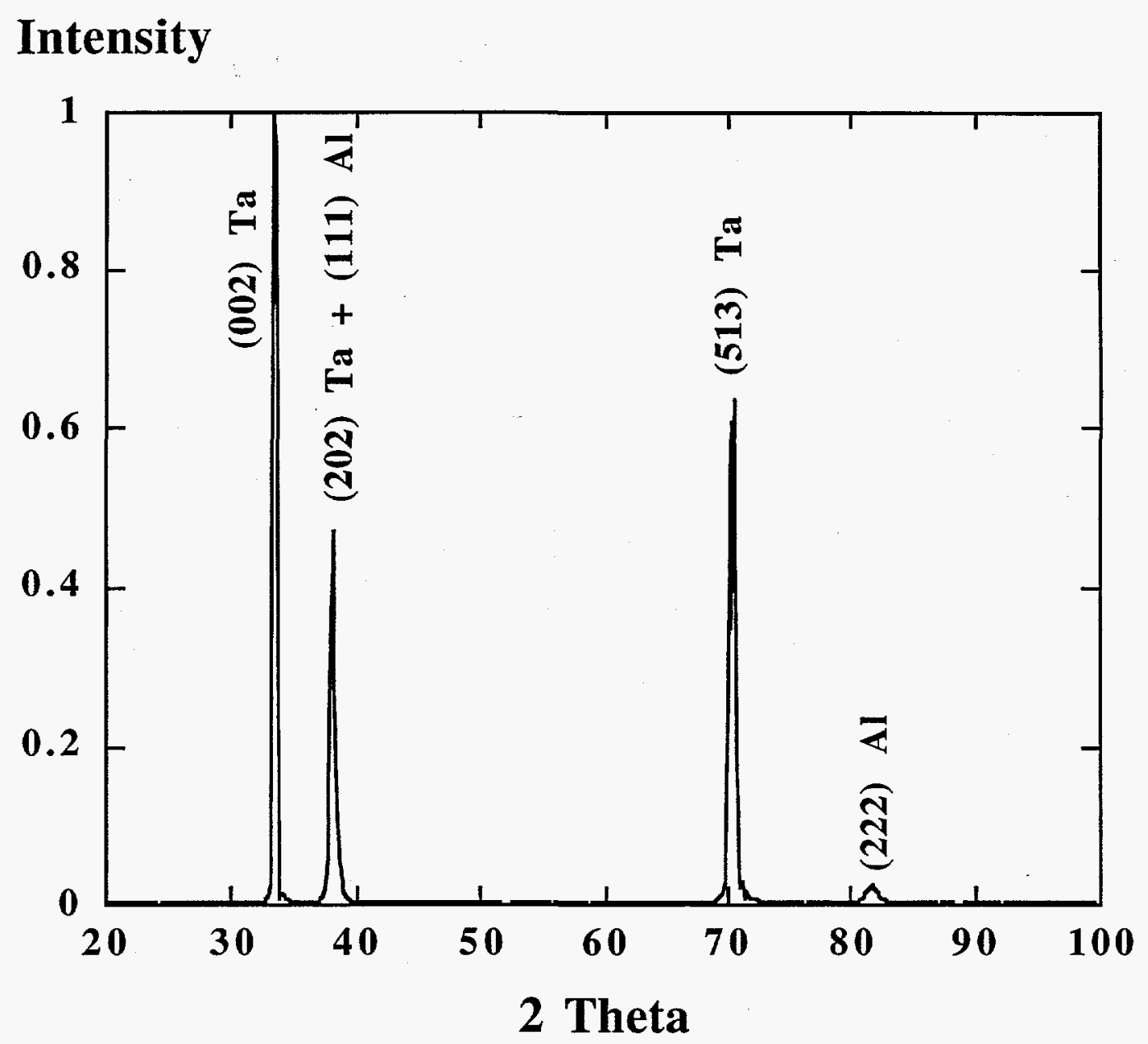

(b)

(Figure 1 cont'd) 


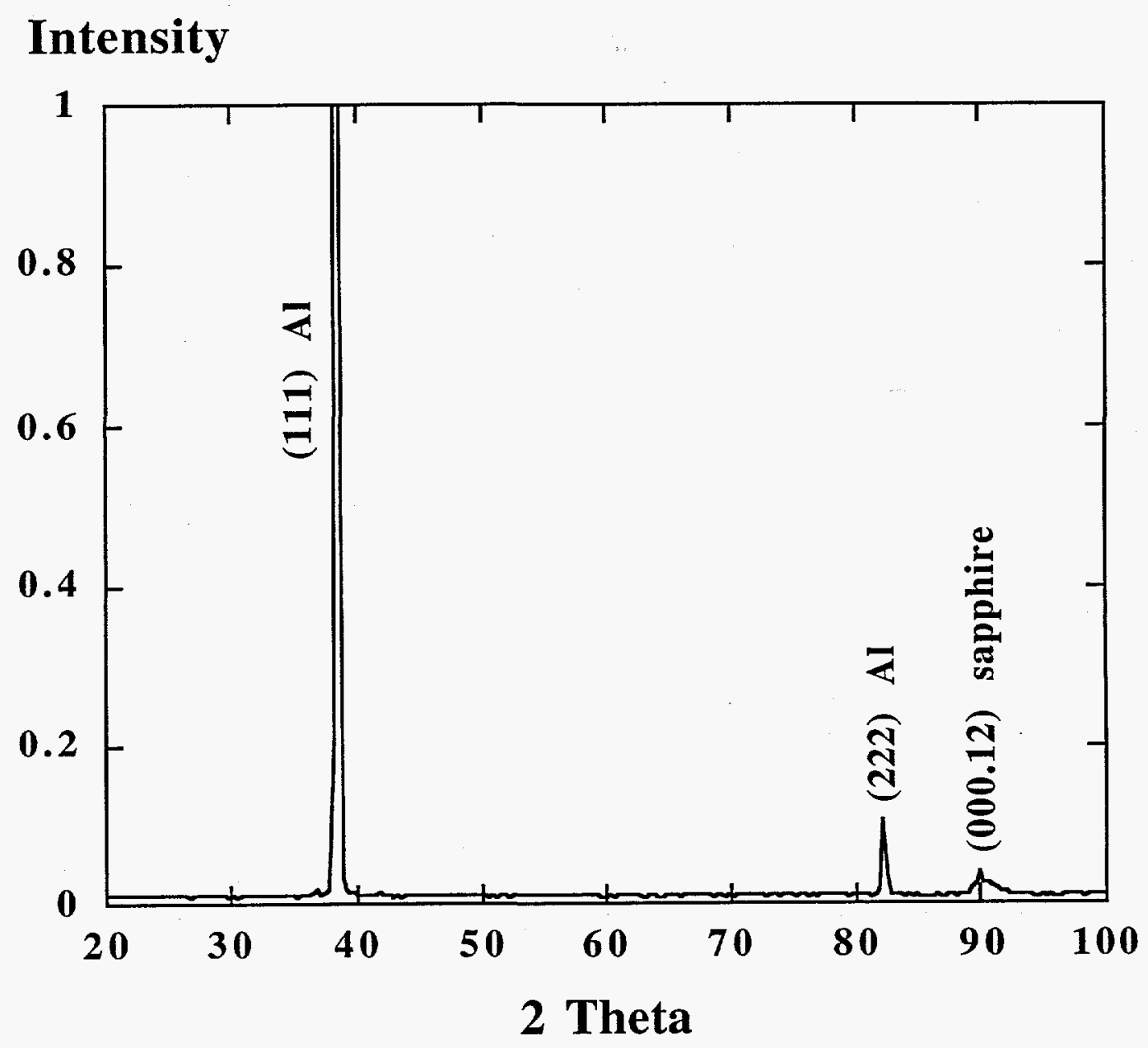

(c)

(Figure 1 cont'd) 


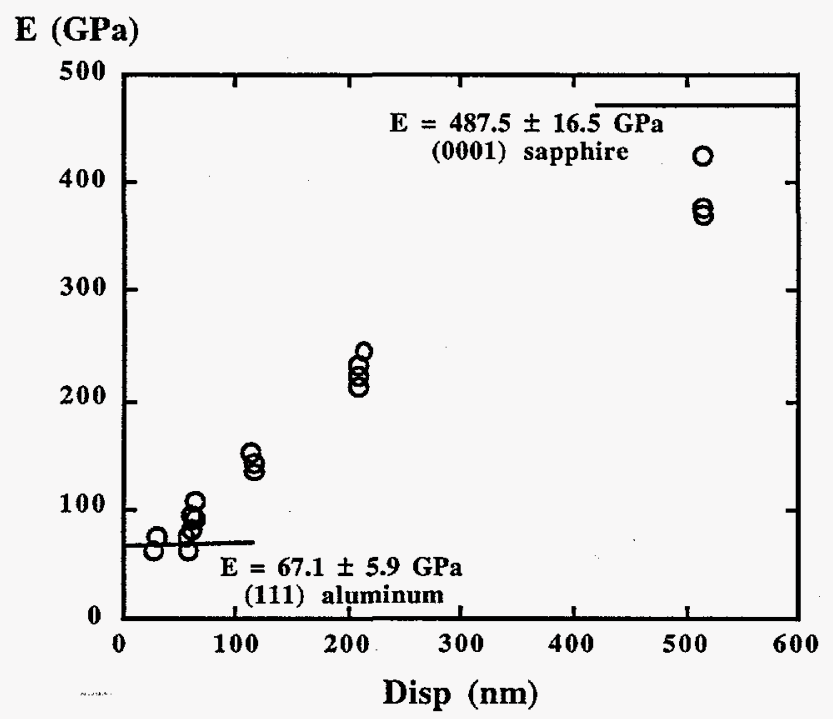

(a)

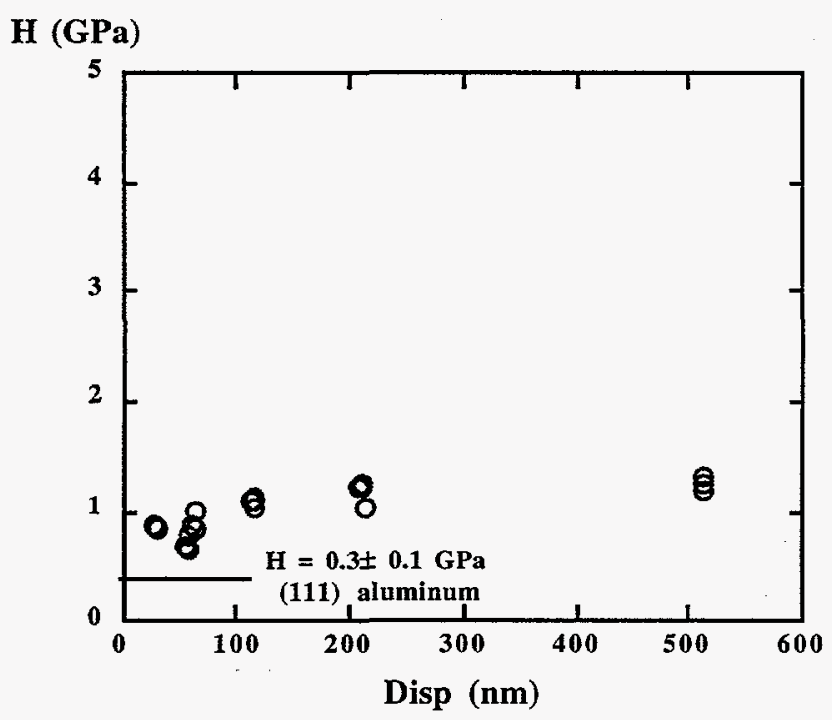

(b)

Figure 2. Nanoindentation techniques were used to calculate the elastic modulus (a) and hardness (b) values for the $500 \mathrm{~nm}$ thick Al films on sapphire substrates. Reference values for the corresponding bulk material properties are indicated by the horizontal lines. 
E (GPa)

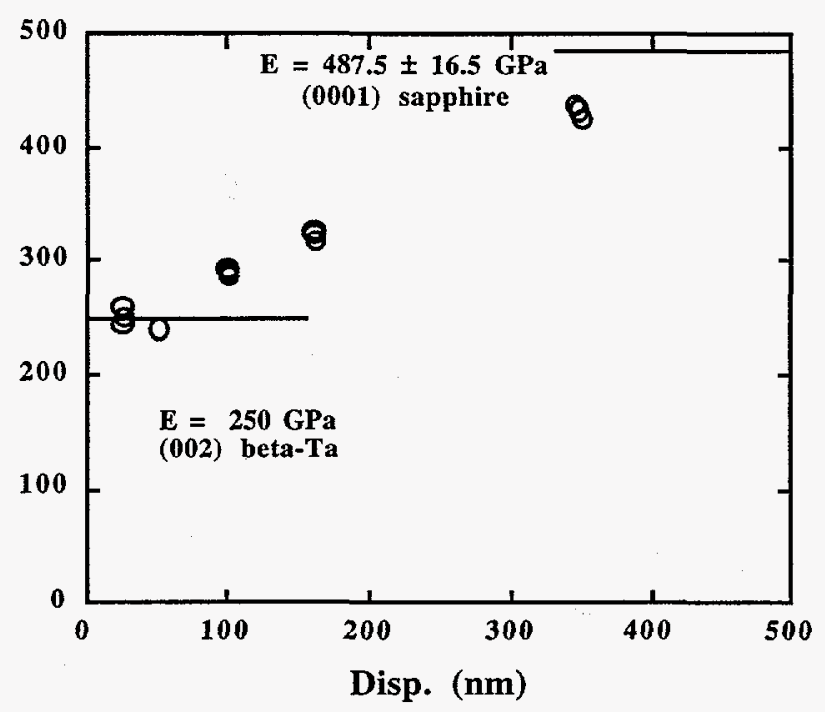

(a)

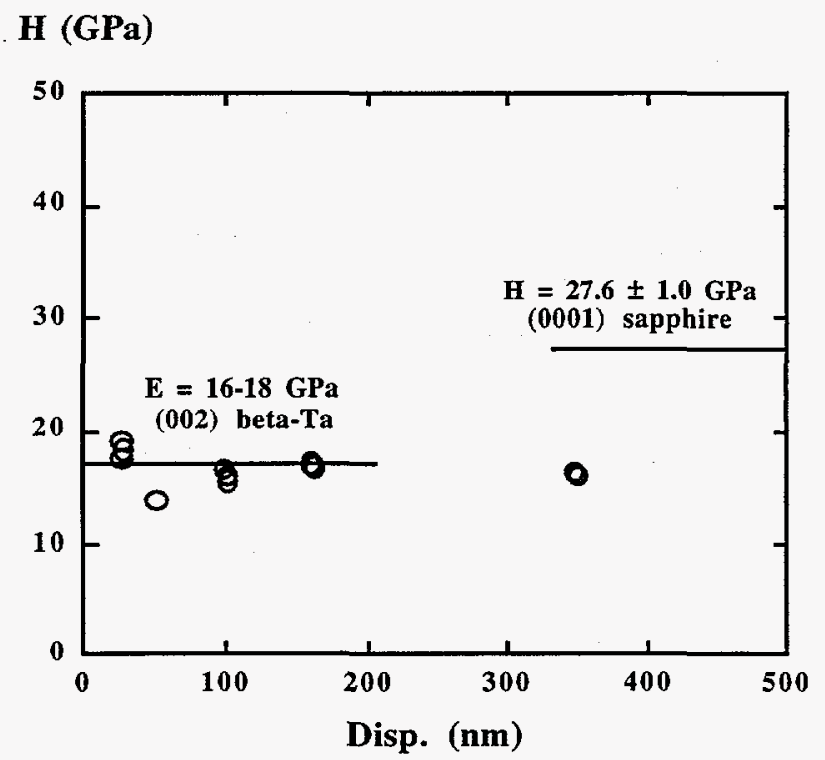

(b)

Figure 3. Nanoindentation techniques were used to calculate the elastic modulus (a) and hardness (b) values for $1000 \mathrm{~nm}$ thick $\beta$-Ta films on sapphire substrates. Reference values for the corresponding bulk material properties are indicated by the horizontal lines 


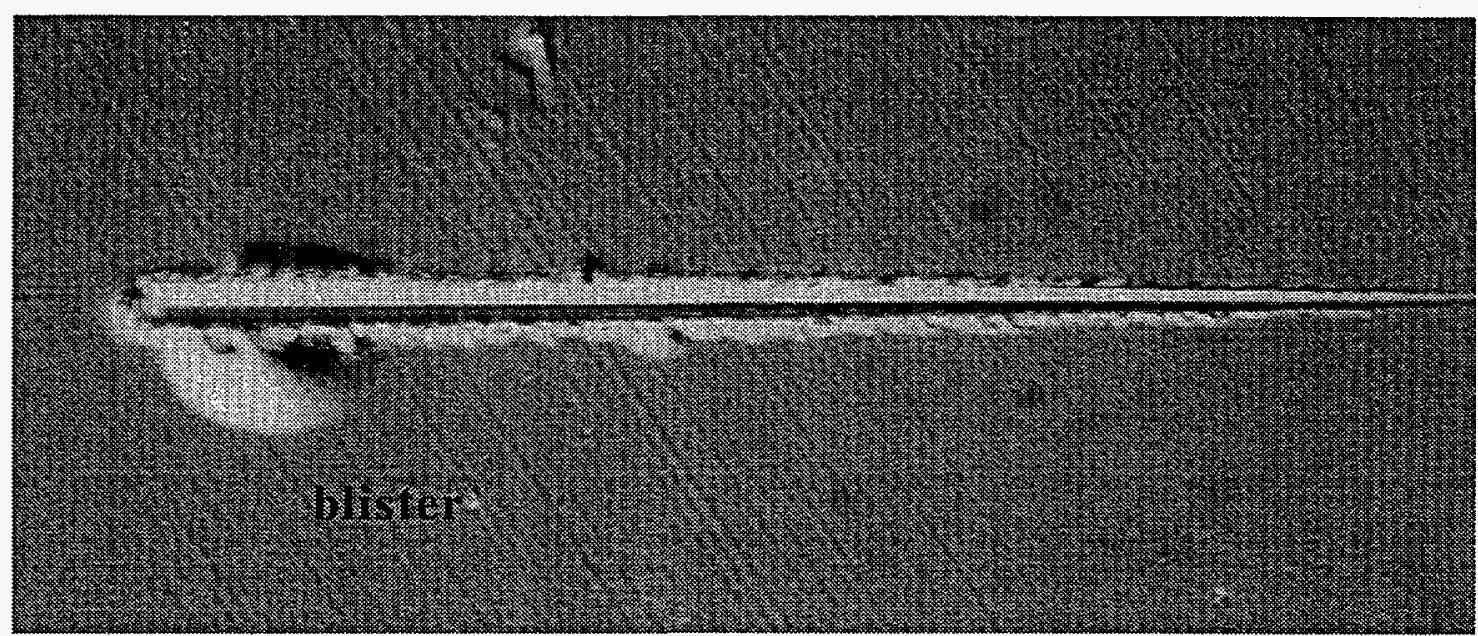

(a)

$\overline{2} \bar{\mu} \bar{m}$

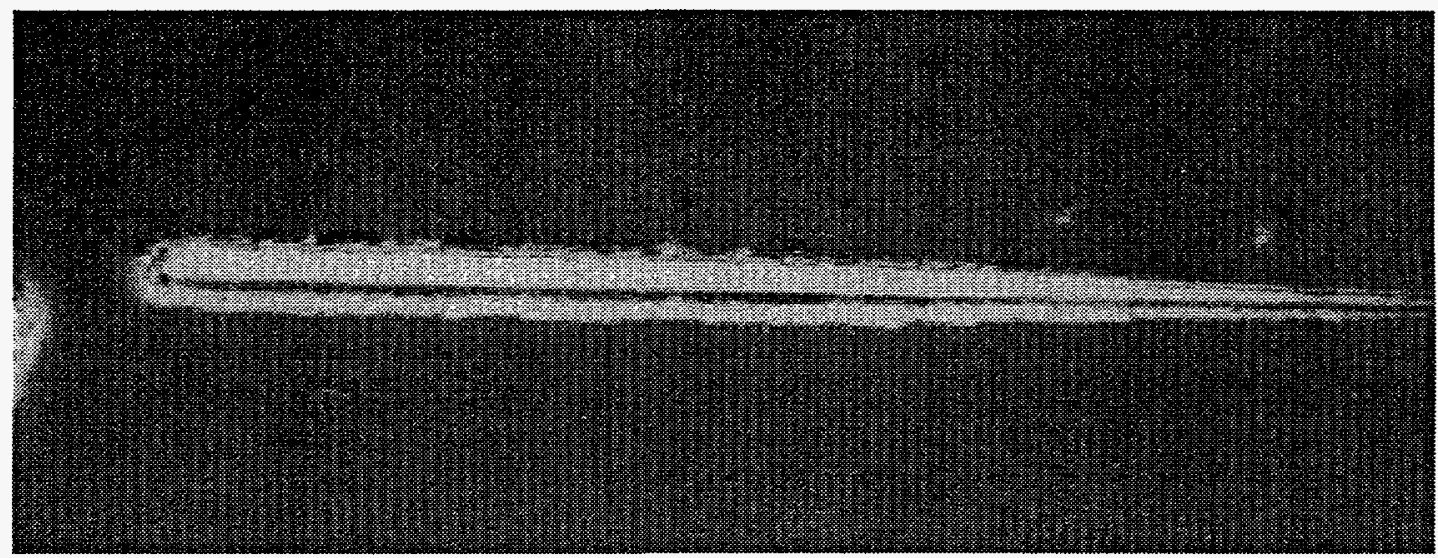

(b)

$\overline{2} \overline{5} \overline{\mu m}$

Figure 4. Microscratch tests of the $178 \mathrm{~nm} \mathrm{Al} \mathrm{films} \mathrm{on} \mathrm{sapphire} \mathrm{were} \mathrm{used} \mathrm{to} \mathrm{evaluate}$ the effects of 5-10 nm of carbon at the interface. Light micrographs show a blister which formed as a $100 \mu \mathrm{m}$ long scratch was made in the film with a 5-10 nm layer of carbon at the interface (a) but not in the one with a "clean" sapphire substrate (b). 


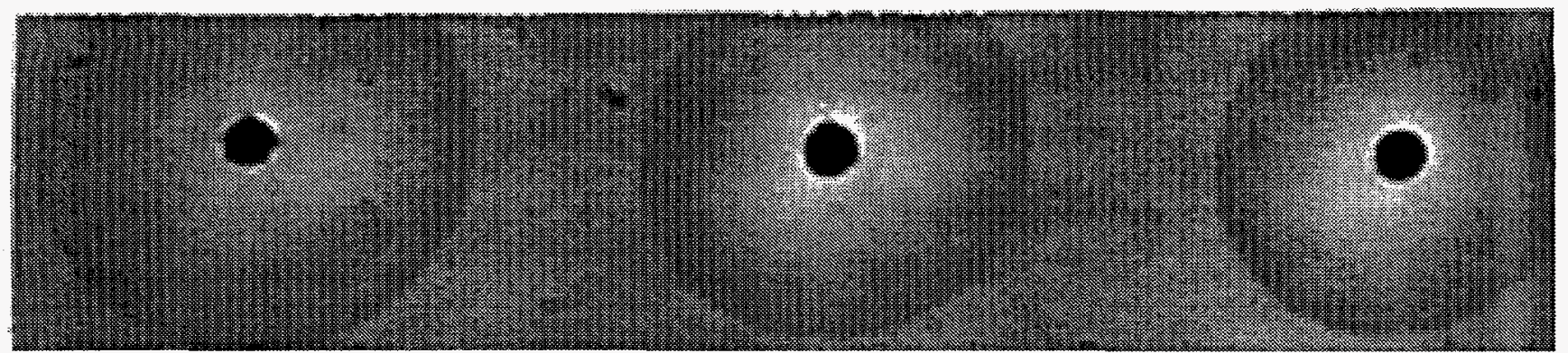

$50 \bar{m}$

(a)

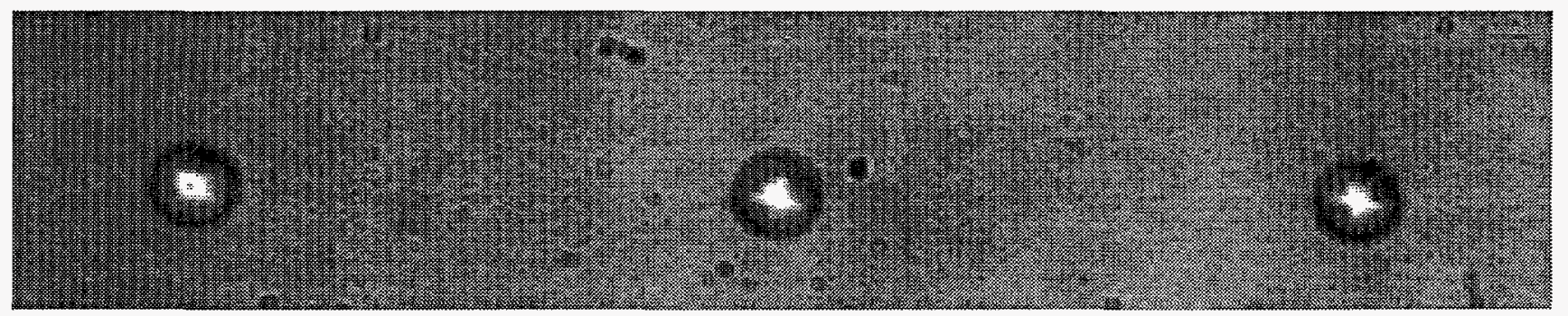

$-\overline{\mathbf{5}} \overline{\boldsymbol{\mu}} \overline{\mathrm{m}}$

(b)

Figure 5. Nanoindentation tests were used to induced blisters in the samples with $\mathrm{Ta} / \mathrm{Al}$ films on sapphire under a $250 \mathrm{mN}$ load. Larger diameter blisters are observed in the light micrograph images in the sample with $10-20 \mathrm{~nm}$ of carbon at the interface (a) than in the sample with the "clean" interface (b). 


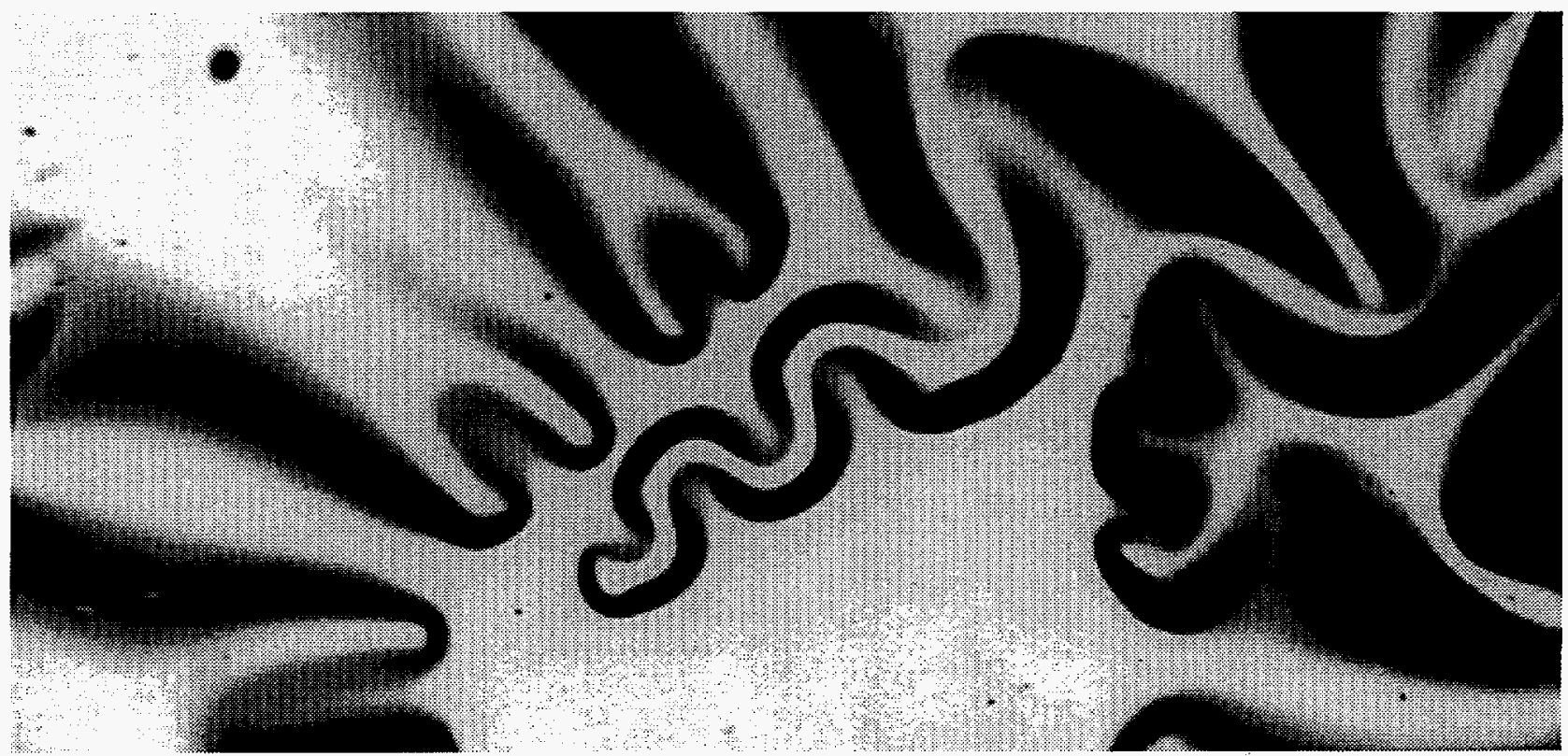

Figure 6. The Ta coated $\mathrm{Al}$ films continued to delamination over time in samples with carbon at the sapphire interface. Classic "telephone cord" blisters, typically observed in highly stressed films, are show in this light micrograph of the film surface. 


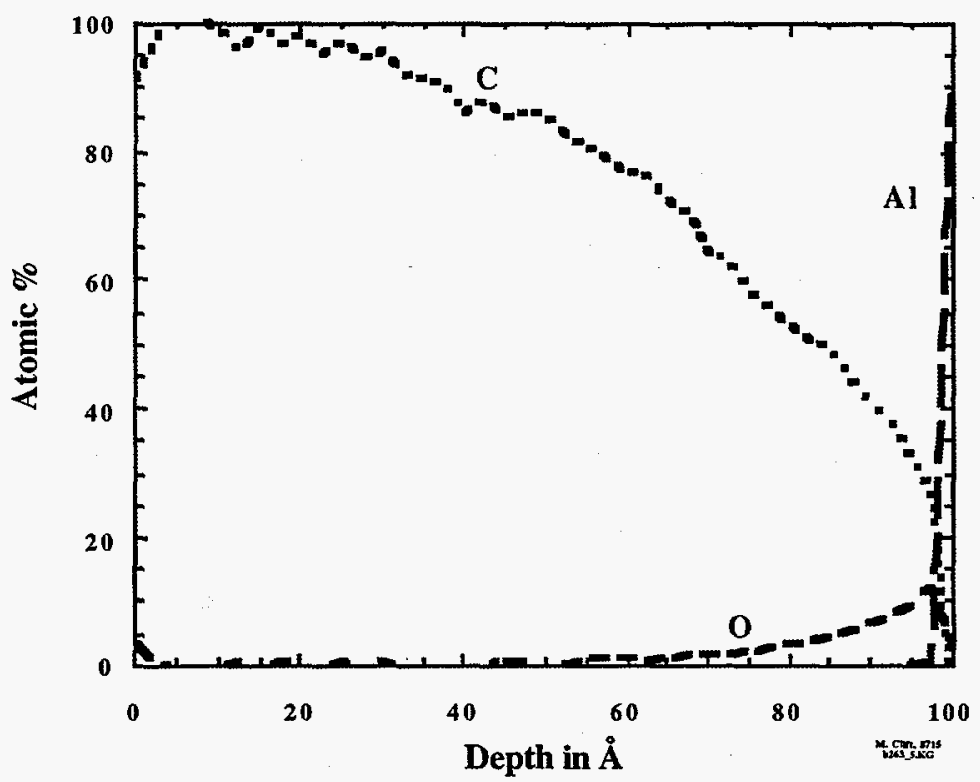

(a)

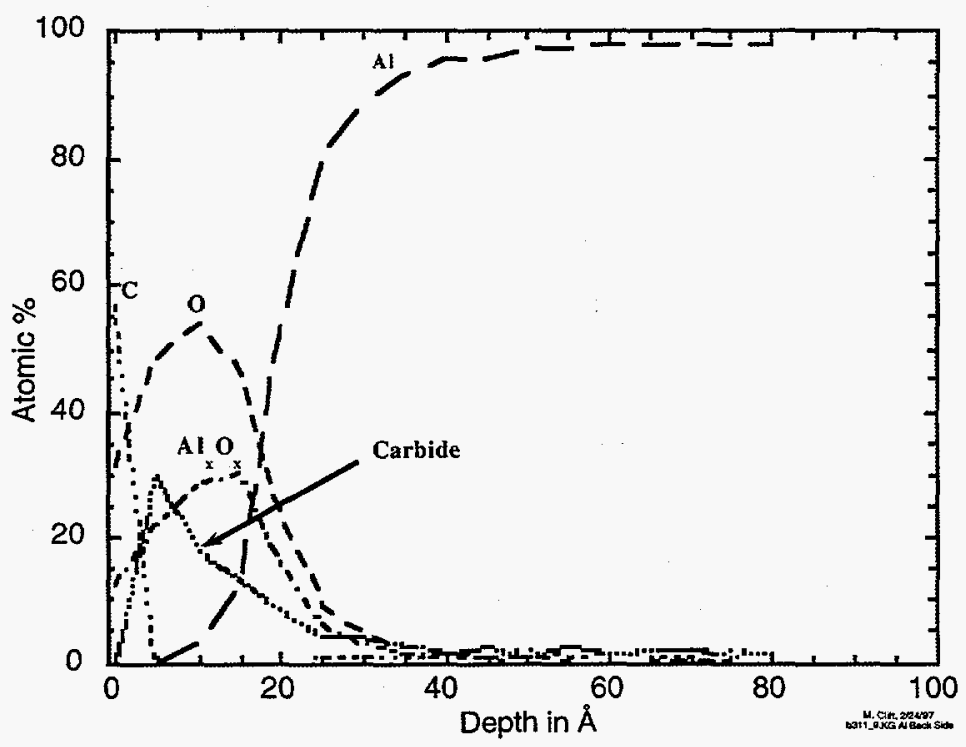

(b)

Figure 7. Separation of the film from the substrate allowed sputtering Auger analysis of the delaminated regions. A $10 \mathrm{~nm}$ residual carbon layer remains on the sapphire substrate interface surface (a). On the $\mathrm{Al}$ film interface surface (b), a $5 \mathrm{~nm}$ layer of carbon layer remains, indicating the fracture occurred in the carbon layer. Carbide formation is noted between the carbon and $\mathrm{Al}$. 